\title{
APPLICATION OF NUMERICAL METHODS FOR THE ANALYSIS OF DAMPED PARALLEL RLC CIRCUIT
}

\author{
J. Kafle ${ }^{1}$, B. K. Thakur ${ }^{1}$, I. B. Bhandari ${ }^{2,3 *}$ \\ ${ }^{I}$ Central Department of Mathematics, Tribhuvan University, Kirtipur, Nepal \\ ${ }^{2}$ Central Department of Physics, Tribhuvan University, Kirtipur, Nepal \\ ${ }^{3}$ Department of Applied Sciences, Purwanchal Campus, Tribhuvan University, Dharan, Nepal \\ "Corresponding author: bhandari.indra@gmail.com
}

(Received: November 21, 2020; Revised: April 20, 2021; Accepted: April 30, 2021)

\begin{abstract}
A sudden application of sources results in time-varying currents and voltages in the circuit known as transients. This phenomenon occurs frequently during switching. A simple circuit constituting a resistor, an inductor, and a capacitor is termed an RLC circuit. It may be in parallel or series configuration or both. Different values of damping factors determine the different nature of the transient response. We applied different numerical solution methods such as explicit (forward) Euler method, third-order Runge-Kutta (RK3) method, and Butcher's fifth-order Runge-Kutta (BRK5) method to approximate the solution of second-order differential equation with initial value problem (IVP). We thoroughly compared the numerical solutions obtained by these methods with the necessary visualization and analysis of error. We also examined the superiority of these methods over one another and the appropriateness of numerical methods for different damping conditions is explored. With high accuracy of the approximation and thorough analysis of the observation, we found Butcher's fifth-order Runge-Kutta (BRK5) method to be the best numerical technique. Regarding the different values of damping factors, we considered the further possibility of discussion and analysis of this iterative method.
\end{abstract}

Keywords: Damping condition, DC source, Iterative methods, Parallel RLC circuit, Transient analysis.

\section{INTRODUCTION}

There is a significant and crucial role of the differential equation while considering the problem of mathematical modeling in the field of engineering, mathematics, and applied science (Ahamad \& Charan, 2019; Kendall et al., 2009; Pokhrel et al., 2020a). While encountering the differential equations in modeling, almost all appears to be nonlinear. It is a needle in a haystack task to solve a nonlinear partial differential equation (PDE) analytically (Ahamad \& Charan, 2019; Pokhrel et al., 2020a, 2020b). Naiver-Stokes equation is a typical example of a secondorder nonlinear partial differential equation that can't be solved analytically (Kendall et al., 2009; Hossain et al., 2017b; Pokhrel et al., 2020). Therefore, a pragmatic and more rigorous approach is to be devised to find some approximation of such difficult problems. One such approach is the numerical method (Hossain et al., 2017a).

Time-varying currents and voltages from a sudden application of sources induce a transient or momentary fluctuation of energy upon the electrical circuit. This event occurs usually during switching (Suhag, 2013). This sudden upsurge of energy in the circuitry is not a good environment for sensitive electrical components such as an inductor, capacitor, resistor, diode, and transistors that are millions in number and embedded inside integrated circuits (Deshpande, 2014). The whole system could be destabilized and the electrical system could be rendered to an unsteady state. The role of transient analysis comes into play in such a scenario as it analyses the response of electrical components under these unsteady conditions (Kee \& Ranom, 2018).

Thus, a transient analysis methodology is to measure the performance of electrical circuits (Balota \& Grebovic, 2016). If the variables do not change with time, then the state of a system is in a steady state. Otherwise, it is in an unsteady state. The current in the parallel LCR (inductor, capacitor, and resistor) circuit depends not only on the magnitude of the applied electromotive force (emf) but also on its frequency (Lamichhane, 2019; Adhikari et al., 2018). The electrical component in daily household equipment such as mixture, iron, refrigerator, mobile charger, etc. is comparatively larger and heavier dosed to handle the transient ailments. However, the transient occurring in a nano-scale inside a microprocessor, hard disk, and motherboard could be fatal to the existence of the system (Henry et al., 2019). The response of the system by changing the conditions from one steady-state value to another for the transient analysis of a secondorder RLC circuit was observed. The author insisted on the efficiency of the RK method in solving second order differential equation.

The RK4 method was used with different time steps size $h$ for the transient analysis of series RLC circuits under different damping conditions (Kee \& Ranom, 2018). The accuracy of the RK4 method was calculated gradually by decimating the step size. Thus by decreasing the step $h$ or 
increasing the number of step ( $n$ ) degree of accuracy and efficiency of the improved RK4 method was more favored for solving transient analysis of the electrical circuit. Two numerical methods viz. Heun's method and the RungeKutta method were employed for the task of transient analysis of second-order RLC circuit (Henry et al., 2019). Though Heun's method reached the stable limit first by converging faster, Runge-Kutta $4^{\text {th }}$ order method proved to be more accurate. Runge-Kutta method was thus recommended for transient analysis of the complex electric circuit.

Ahamad and Charan (2019) utilized the fifth order RungeKutta method (RK5) to solve the initial value problem for fourth-order ODE. Kamruzzaman and Nath (2018) compared the numerical solution with the exact solution of an ODE with IVP by employing the modified Euler and Runge-Kutta method. Maffezzoni et al., (2007) found a novel approach to accurate time-domain simulation of a nonlinear circuit by employing high order implicit RungeKutta method. They briefly reviewed the stability and accuracy of this RK method. Kafle et al. (2020) compared the different iterative methods to analyze the damping conditions of series RLC circuits under the transient situation with DC source and they found the best iterative method as BRK5 to solve the second-order ODE of the series RLC circuit. They observed the three damping conditions by using the BRK5 method. Alizadeh et al. (2020) studied the Laplace transformation solution of Caputo-Fabrizio sectional derivative to study the transient response of parallel RLC circuits. They compared the graph obtained for solutions of a different order of fractional derivative with the usual solutions. Elton (2017) started with the basics concept of the RLC circuit and ended with the concept of circuit design. He analyzed both series and parallel RLC circuits with practical applications using advanced calculus to aid in predetermined results.

In the presented work, we employed a second-order ODE to model a parallel RLC circuit with a DC source. For solving IVP of ODE and transient analysis, we first compared the three iterative methods: Explicit Euler, third-order Runge-Kutta (RK3), and Butcher fifth-order Runge-Kutta (BRK5). BRK5 method is observed to be the best method as it gives the least error compared to the other two methods. BRK5 method is then chosen to analyze the three damping conditions of the RLC circuit. Our approach in this paper is less analytical and more numerical among the various iterative methods for solving the differential equation. The second section comprises the theoretical approach and three iterative methods with the necessary numerical formulation. The third section depicts the simulation result and comparison of the abovementioned method. The fourth section culminates the conclusion and finding of this work.

\section{MATERIALS AND METHODS}

\section{Mathematical theory}

An RLC circuit constitutes of three electrical elements: a resistor, an inductor, and a capacitor. It is a second-order circuit. These circuits are the most popular as they are applied to construct oscillators and tuners of radio or audio receivers (Suhag, 2013). In Fig. 1, the electrical elements resistor $(\mathrm{R})$, inductor $(\mathrm{L})$, and capacitor $(\mathrm{C})$ are connected in parallel with the D.C. source $\left(V_{s}\right)$, which we call the parallel RLC circuit. A circuit equation is drawn to undertake the analytical solution part of a transient analysis (Kee \& Ranom, 2018). An ordinary electrical circuitry could contain thousands of components. Therefore, any analytical solution in such RLC circuits is virtually impossible. In such a scenario, numerical methods could offer great relief to the solution of the system (Falade \& Ayodele, 2019). Here, we used possible iterative methods to solve the circuit equation under the terms of transient analysis in an RLC circuit and compare different methods.

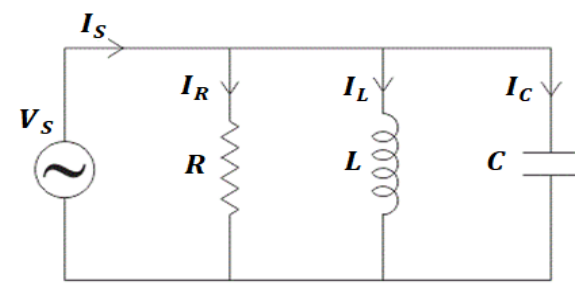

Fig. 1. Parallel RLC circuit

The Kirchhoff's Current Law (Kee \& Ranom, 2018) is applied around the loop for $t>0$, in which the total current of the circuit in Fig. 1 is calculated by the following;

$\mathrm{I}_{\mathrm{S}}=\mathrm{I}_{\mathrm{R}}+\mathrm{I}_{\mathrm{L}}+\mathrm{I}_{\mathrm{C}} \cdots \cdots \cdots(1)$

Where, $I_{S}$ is the source current $I_{R}, I_{L}$ and $I_{C}$ are the current through resistor, inductor, and capacitor respectively.

The differential equation of the RLC in Fig. 1 is based on the method of loop currents where the fundamental relationship between the current, and the individual circuit elements (Maria Selvam \& Vignesh, 2018) are given by

Resistance: $I_{R}=\frac{1}{R} v$

Capacitance: $\mathrm{I}_{\mathrm{C}}=\mathrm{C} \frac{\mathrm{dv}}{\mathrm{dt}}$

Inductance: $\mathrm{I}_{\mathrm{L}}=\frac{1}{\mathrm{~L}} \int \mathrm{vdt}$

Where, $v$ is the voltage drop across each element viz. capacitor, resistor, inductor. Substituting these values in equation (1), we get; 


$$
\frac{1}{\mathrm{R}} \mathrm{v}+\frac{1}{\mathrm{~L}} \int \mathrm{vdt}+\mathrm{C} \frac{\mathrm{dv}}{\mathrm{dt}}=\mathrm{I}_{\mathrm{S}}
$$

Differentiate on both sides, we get the second-order differential equation of the RLC circuit with constant coefficients is written as (Santiago, 2013).

$\frac{\mathrm{d}^{2} \mathrm{v}}{\mathrm{dt}^{2}}+\frac{1}{\mathrm{RC}} \frac{\mathrm{dv}}{\mathrm{dt}}+\frac{1}{\mathrm{LC}} \mathrm{v}=0$

with $v(0)=6, i(0)=0$, and $\frac{\mathrm{d} v(0)}{\mathrm{dt}}=-12$

The parallel RLC circuit is analyzed to determine its transient characteristics once the switch is closed. Equation (2) can be solved using different iterative methods (Henry et al., 2019).

The damping factor is responsible for the amount by which the oscillation of a system gradually decreases with time (t). Transient response is dependent on the value of the damping factor $(\zeta)$ (Henry et al., 2019). In a parallel RLC circuit, the damping factor is given by

$\zeta=\frac{\alpha}{\omega_{\mathrm{o}}} \quad$ where, $\quad \alpha=\frac{1}{2 \mathrm{RC}}$ (damping coefficient) and $\omega_{\mathrm{o}}=\frac{1}{\sqrt{\mathrm{LC}}} \quad$ (resonant frequency).

Then, $\zeta=\frac{1}{2 \mathrm{R}} \sqrt{\frac{\mathrm{L}}{\mathrm{C}}}$

The system is (i) overdamped when $\zeta>1$, (ii) critically damped when $\zeta=1$, and (iii) underdamped when $\zeta<1$ (Suhag, 2013).

\section{Numerical methodologies}

In this section, we introduce the Euler method (explicit), Third-order Ruge-Kutta method (RK3), and Butcher's fifth-order Runge-Kutta (BRK5) method to solve initial value problems (IVP) for ordinary differential equations (ODE) (Boyce \& Di Prima, 2012; Butcher \& Goodwin, 2008; Kafle et al., 2020).

The forward Euler formula (Butcher \& Goodwin, 2008; Kafle et al., 2020) is

$$
\mathrm{y}_{\mathrm{n}+1}=\mathrm{y}_{\mathrm{n}}+\mathrm{hf}\left(\mathrm{t}_{\mathrm{n}}, \mathrm{y}_{\mathrm{n}}\right)
$$

The third order Runge-Kutta formula (Senthilnatha, 2018; Kafle et al., 2021) is

$$
\begin{aligned}
& \mathrm{y}_{\mathrm{n}+1}=\mathrm{y}_{\mathrm{n}}+\mathrm{h}\left[\frac{\mathrm{k}_{1}}{6}+\frac{2 \mathrm{k}_{2}}{3}+\frac{\mathrm{k}_{3}}{6}\right] \ldots \ldots(5) \\
& \text { where, } \mathrm{k}_{1}=\mathrm{f}\left(\mathrm{t}_{\mathrm{n}}, \mathrm{y}_{\mathrm{n}}\right), \mathrm{k}_{2}=\mathrm{f}\left(\mathrm{t}_{\mathrm{n}}+\frac{\mathrm{h}}{2}, \mathrm{y}_{\mathrm{n}}+\frac{\mathrm{h}}{2} \mathrm{k}_{1}\right), \\
& \mathrm{k}_{3}=\mathrm{f}\left(\mathrm{t}_{\mathrm{n}}+\mathrm{h}, \mathrm{y}_{\mathrm{n}}-\mathrm{hk}_{1}+2 \mathrm{hk}_{2}\right)
\end{aligned}
$$

The Butcher fifth-order Runge-Kutta formula (Henry et al., 2019; Butcher \& Goodwin, 2008; Kafle et al., 2021) is

$$
\mathrm{y}_{\mathrm{n}+1}=\mathrm{y}_{\mathrm{n}}+\frac{\mathrm{h}}{90}\left(7 \mathrm{k}_{1}+32 \mathrm{k}_{3}+12 \mathrm{k}_{4}+32 \mathrm{k}_{5}+7 \mathrm{k}_{6}\right) .
$$

Where,

$$
\begin{aligned}
& \mathrm{t}_{\mathrm{n}+1}=\mathrm{t}_{\mathrm{n}}+\mathrm{h}, \mathrm{k}_{1}=\mathrm{f}\left(\mathrm{t}_{\mathrm{n}}, \mathrm{y}_{\mathrm{n}}\right), \\
& \mathrm{k}_{2}=\mathrm{f}\left(\mathrm{t}_{\mathrm{n}}+\frac{\mathrm{h}}{4}, \mathrm{y}_{\mathrm{n}}+\frac{\mathrm{h}}{4} \mathrm{k}_{1}\right), \\
& \mathrm{k}_{3}=\mathrm{f}\left(\mathrm{t}_{\mathrm{n}}+\frac{\mathrm{h}}{4}, \mathrm{y}_{\mathrm{n}}+\frac{1}{8} \mathrm{hk}_{1}+\frac{1}{8} \mathrm{hk}_{2}\right), \\
& \mathrm{k}_{4}=\mathrm{f}\left(\mathrm{t}_{\mathrm{n}}+\frac{\mathrm{h}}{2}, \mathrm{y}_{\mathrm{n}}-\frac{1}{2} \mathrm{hk}_{2}+\mathrm{hk}_{3}\right), \\
& \mathrm{k}_{5}=\mathrm{f}\left(\mathrm{t}_{\mathrm{n}}+\frac{3 \mathrm{~h}}{4}, \mathrm{y}_{\mathrm{n}}+\frac{3}{16} \mathrm{hk}_{1}+\frac{9}{16} \mathrm{hk}_{4}\right), \\
& \mathrm{k}_{6}=\mathrm{f}\left(\mathrm{t}_{\mathrm{n}}+\mathrm{h}, \mathrm{y}_{\mathrm{n}}-\frac{3}{7} \mathrm{hk}_{1}+\frac{2}{7} \mathrm{hk}_{2}+\frac{12}{7} \mathrm{hk}_{3}-\frac{12}{7} \mathrm{hk}_{4}+\frac{8}{7} \mathrm{hk}_{5}\right)
\end{aligned}
$$

It can extend the above discussed iterative methods for the solution of higher-order IVP for ODE and system of IVP for ODEs (Hossain et al., 2017a, 2017b; Kafle et al., 2021).

\section{Numerical formulation of parallel RLC circuit}

$$
\text { Let, } v=x \text { and } \frac{d v}{d t}=\frac{y}{c}
$$

Then equation (2) becomes

$$
\frac{\mathrm{dy}}{\mathrm{dt}}=\frac{\mathrm{v}_{\mathrm{S}}}{\mathrm{LC}}-\frac{\mathrm{y}}{\mathrm{RC}}-\frac{\mathrm{x}}{\mathrm{L}}
$$

Hence, equations (7) and (8) form a system of the firstorder differential equation (Henry et al., 2019; Kafle et al., 2021).

Let, $\mathrm{f}=\frac{\mathrm{dv}}{\mathrm{dt}}=\frac{\mathrm{y}}{\mathrm{c}}$ and $\mathrm{g}=\frac{\mathrm{dy}}{\mathrm{dt}}=\frac{\mathrm{v}_{\mathrm{S}}}{\mathrm{LC}}-\frac{\mathrm{y}}{\mathrm{RC}}-\frac{\mathrm{x}}{\mathrm{L}}$

\section{Euler's method for RLC circuit}

$$
\begin{aligned}
& x_{i+1}=x_{i}+h f\left(t_{i}, x_{i}, y_{i}\right) \\
& y_{i+1}=y_{i}+h g\left(t_{i}, x_{i}, y_{i}\right)
\end{aligned}
$$

where $h$ is the time step size.

\section{RK3 method for RLC circuit}

$$
\begin{aligned}
& \mathrm{x}_{\mathrm{i}+1}=\mathrm{x}_{\mathrm{i}}+\left(\mathrm{f}_{1}+4 \mathrm{f}_{2}+\mathrm{f}_{3}\right) / 6 \\
& \mathrm{y}_{\mathrm{i}+1}=\mathrm{y}_{\mathrm{i}}+\left(\mathrm{g}_{1}+4 \mathrm{~g}_{2}+\mathrm{g}_{3}\right) / 6, \text { where, } \\
& \mathrm{f}_{1}=\mathrm{hf}\left(\mathrm{t}_{\mathrm{i}}, \mathrm{x}_{\mathrm{i}}, \mathrm{y}_{\mathrm{i}}\right), \mathrm{g}_{1}=\mathrm{hg}\left(\mathrm{t}_{\mathrm{i}}, \mathrm{x}_{\mathrm{i}, \mathrm{y}_{\mathrm{i}}}\right), \\
& \mathrm{f}_{2}=\mathrm{hf}\left(\left(\mathrm{t}_{\mathrm{i}}+\frac{\mathrm{h}}{2}\right),\left(\mathrm{x}_{\mathrm{i}}+\frac{\mathrm{f}_{1}}{2}\right),\left(\mathrm{y}_{\mathrm{i}}+\frac{\mathrm{g}_{1}}{2}\right)\right),
\end{aligned}
$$


$\mathrm{g}_{2}=\mathrm{hg}\left(\left(\mathrm{t}_{\mathrm{i}}+\frac{\mathrm{h}}{2}\right),\left(\mathrm{x}_{\mathrm{i}}+\frac{\mathrm{f}_{1}}{2}\right),\left(\mathrm{y}_{\mathrm{i}}+\frac{\mathrm{g}_{1}}{2}\right)\right)$,

$f_{3}=h f\left(\left(t_{i}+h\right),\left(x_{i}-f_{1}+2 f_{2}\right),\left(y_{i}-g_{1}+2 g_{2}\right)\right)$,

and $g_{3}=h g\left(\left(t_{i}+h\right),\left(x_{i}-f_{1}+2 f_{2}\right),\left(y_{i}-g_{1}+2 g_{2}\right)\right)$

\section{Formulating BRK5 method for RLC circuit}

$$
\begin{aligned}
& x_{i+1}=x_{i}+\left(7 f_{1}+32 f_{3}+12 f_{4}+32 f_{5}+7 f_{6}\right) / 90 \\
& \mathrm{y}_{\mathrm{i}+1}=\mathrm{y}_{\mathrm{i}}+\left(7 \mathrm{~g}_{1}+32 \mathrm{~g}_{3}+12 \mathrm{~g}_{4}+32 \mathrm{~g}_{5}+7 \mathrm{~g}_{6}\right) / 90 \\
& f_{1}=h f\left(t_{i}, x_{i}, y_{i}\right), \quad g_{1}=h g\left(t_{i}, x_{i}, y_{i}\right), \\
& \text { Where, } \mathrm{f}_{2}=\mathrm{hf}\left(\left(\mathrm{t}_{\mathrm{i}}, \frac{\mathrm{h}}{4}\right),\left(\mathrm{x}_{\mathrm{i}}, \frac{\mathrm{f}_{1}}{4}\right),\left(\mathrm{y}_{\mathrm{i}}, \frac{\mathrm{g}_{1}}{4}\right)\right) \text {, } \\
& \mathrm{g}_{2}=\mathrm{hg}\left(\left(\mathrm{t}_{\mathrm{i}}+\frac{\mathrm{h}}{4}\right),\left(\mathrm{x}_{\mathrm{i}}+\frac{\mathrm{f}_{1}}{4}\right),\left(\mathrm{y}_{\mathrm{i}}+\frac{\mathrm{g}_{1}}{4}\right)\right), \\
& \mathrm{f}_{3}=h \mathrm{f}\left(\left(\mathrm{t}_{\mathrm{i}}+\frac{\mathrm{h}}{4}\right),\left(\mathrm{x}_{\mathrm{i}}+\frac{\mathrm{f}_{1}+\mathrm{f}_{2}}{8}\right),\left(\mathrm{y}_{\mathrm{i}}+\frac{\mathrm{g}_{1}+\mathrm{g}_{2}}{8}\right)\right), \\
& \mathrm{g}_{3}=\mathrm{h} \mathrm{g}\left(\left(\mathrm{t}_{\mathrm{i}}+\frac{\mathrm{h}}{4}\right),\left(\mathrm{x}_{\mathrm{i}}+\frac{\mathrm{f}_{1}+\mathrm{f}_{2}}{8}\right),\left(\mathrm{y}_{\mathrm{i}}+\frac{\mathrm{g}_{1}+\mathrm{g}_{2}}{8}\right),\right. \\
& \mathrm{f}_{4}=\mathrm{hf}\left(\left(\mathrm{t}_{\mathrm{i}}+\frac{\mathrm{h}}{2}\right),\left(\mathrm{x}_{\mathrm{i}}-\frac{\mathrm{f}_{2}}{2}+\mathrm{f}_{3}\right),\left(\mathrm{y}_{\mathrm{i}}-\frac{\mathrm{g}_{2}}{2}+\mathrm{g}_{3}\right)\right), \\
& \mathrm{g}_{4}=\mathrm{hg}\left(\left(\mathrm{t}_{\mathrm{i}}+\frac{\mathrm{h}}{2}\right),\left(\mathrm{x}_{\mathrm{i}}-\frac{\mathrm{f}_{2}}{2}+\mathrm{f}_{3}\right),\left(\mathrm{y}_{\mathrm{i}}-\frac{\mathrm{g}_{2}}{2}+\mathrm{g}_{3}\right)\right), \\
& f_{5}=h f\left(\left(t_{i}+\frac{3 h}{4}\right),\left(x_{i}+\frac{3 f_{1}}{16}+\frac{9 f_{4}}{16}\right),\left(y_{i}+\frac{3 g_{1}}{16}+\frac{9 g_{4}}{16}\right)\right) \\
& g_{5}=h g\left(\left(t_{i}+\frac{3 h}{4}\right),\left(x_{i}+\frac{3 f_{1}}{16}+\frac{9 f_{4}}{16}\right),\left(y_{i}+\frac{3 g_{1}}{16}+\frac{9 g_{4}}{16}\right)\right) \\
& f_{5}=h f\left(\left(t_{i}+\frac{3 h}{4}\right),\left(x_{i}+\frac{3 f_{1}}{16}+\frac{9 f_{4}}{16}\right),\left(y_{i}+\frac{3 g_{1}}{16}+\frac{9 g_{4}}{16}\right)\right) \\
& \mathrm{g}_{5}=\mathrm{h} \mathrm{g}\left(\left(\mathrm{t}_{\mathrm{i}}+\frac{3 \mathrm{~h}}{4}\right),\left(\mathrm{x}_{\mathrm{i}}+\frac{3 \mathrm{f}_{1}}{16}+\frac{9 \mathrm{f}_{4}}{16}\right),\left(\mathrm{y}_{\mathrm{i}}+\frac{3 \mathrm{~g}_{1}}{16}+\frac{9 \mathrm{~g}_{4}}{16}\right)\right)
\end{aligned}
$$

\section{RESULTS AND DISCUSSION}

In the following sub-section, we compare the numerical solution of RLC circuits by above discussed numerical methods with the exact solution and analyze the different characteristics of damping factor by using an iterative method. The time step size used for the simulation is 0.1 second. Fig. 2 describes simulation results of numerical solution of parallel RLC circuit and exact solution in overdamped, critically damped, and underdamped conditions from the top, middle, and bottom respectively. To compare the accuracy of the numerical methods, the computed points of the three numerical methods are taken at a specific time. The computed point of each method is compared with the analytic solution. It observed from Fig. 2 that numerical solutions are more converging with the analytical solution in overdamped conditions and less converging with the analytical solution in underdamped conditions. Therefore, we conclude that numerical methods are more suitable in the overdamped condition. In the Euler method, there is taking slope only. In RK3 method takes the third-order slopes and average of these slopes. In the BRK5 method, it takes the average of the fifth-order slopes. So Butcher method is converging faster than the other two methods.
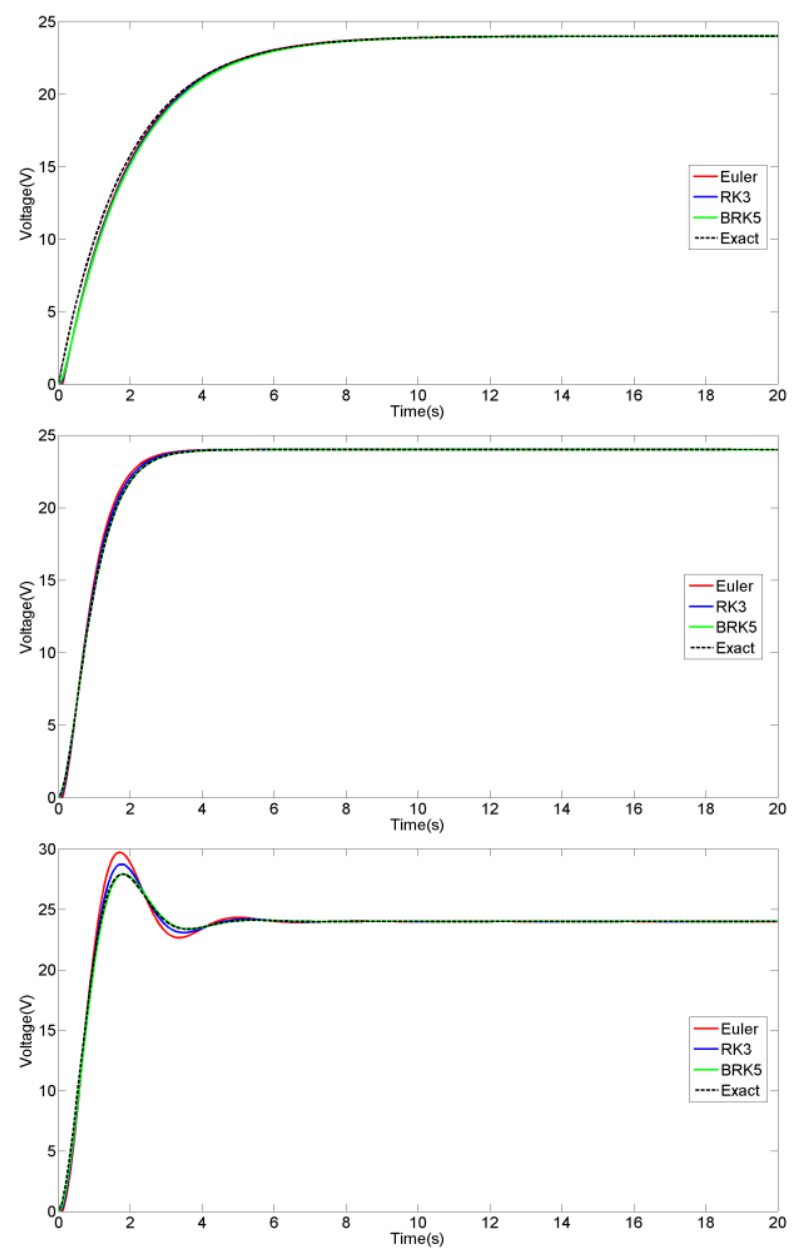

Fig. 2. Comparison of the iterative method with the analytical solution of overdamped (top), critically damped (middle), and underdamped (bottom)

From Fig. 2, it observed that the approximate solution curve obtained from the Butcher fifth-order Runge-Kutta (BRK5) method is converging faster towards the analytical solution in comparison with the other two methods. This shows that there is less error between BRK5 and analytical solution in comparison with the other two methods.

\section{Comparison between analytical solution and numerical methods}

Table 1 contains the data that is used in the simulation of three iterative methods and three damping conditions for the solution of a parallel RLC circuit. 
Table 1. The values of electrical elements of parallel RLC circuit for three conditions (Kee \& Ranom, 2018)

\begin{tabular}{|l|l|l|l|}
\hline \multirow{2}{*}{ Element } & \multicolumn{3}{|c|}{ Value } \\
\cline { 2 - 4 } & Cond-1 & Cond-2 & Cond-3 \\
\hline Resistor & $\begin{array}{l}\text { Under- } \\
\text { damped }\end{array}$ & $\begin{array}{l}\text { Critically } \\
\text { damped }\end{array}$ & $\begin{array}{l}\text { Over- } \\
\text { damped }\end{array}$ \\
\hline $\mathrm{DC}\left(\mathrm{V}_{\mathrm{s}}\right)$ & $6 \mathrm{~V}$ & $6 \mathrm{~V}$ & $6 \mathrm{~V}$ \\
\hline $\mathrm{R}$ & $<1 \Omega$ & $1 \Omega$ & $>4 \Omega$ \\
\hline $\mathrm{L}$ & $1 \mathrm{H}$ & $1 \mathrm{H}$ & $1 \mathrm{H}$ \\
\hline $\mathrm{C}$ & $0.25 \mathrm{~F}$ & $0.25 \mathrm{~F}$ & $0.25 \mathrm{~F}$ \\
\hline$R=$ Resistor, $L=$ Inductor, C= Capacitor, Cond. $=$ Condition
\end{tabular}

Table 2 contains details of simulated results obtained for iterative methods and exact solutions with errors in different time slices. Hence, we concluded that the BRK5 method is a more efficient method to approximate the solution of parallel RLC circuit as the BRK5 method takes the average of fourth-order slopes which gives less error.

In the following section, we consider three damping cases (i.e. underdamped, critically damped, and overdamped) for Butcher fifth-order Runge-Kutta (BRK5) method

\section{Characteristics of damping factor by using BRK5 method}

From Fig. 3, we observed that the under-damped responses are a decaying oscillation that decays at a rate determined by the attenuation $(\alpha)$ by using the BRK5 method. The exponential decay describes the envelope of the oscillation. Here the oscillation is sinusoidal with exponentially decaying amplitude. The critically damped response represents the circuit response that decays in the fastest possible time without going into oscillation. This consideration is important in control systems where it is required to reach the desired state as quickly as possible without overshooting. The over-damped response is a decay of the transient current without oscillation, which reaches the stable state slower than the critically damped case.

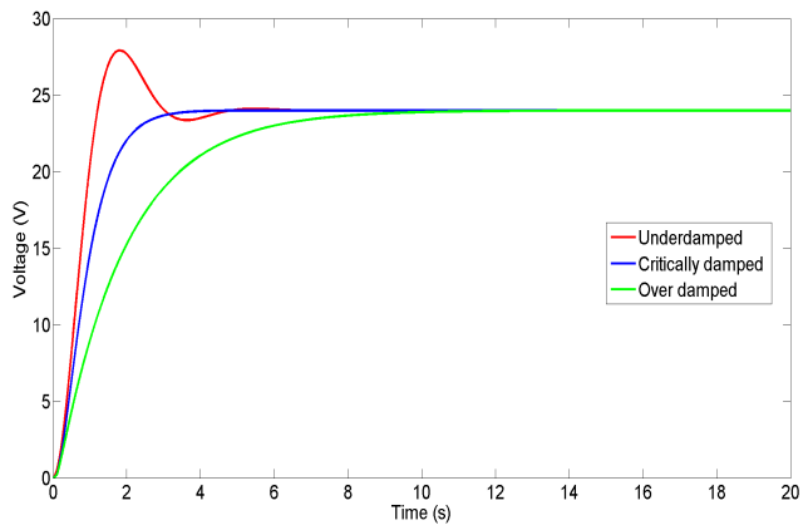

Fig. 3. Comparison of three different damping condition by using BRK5

The quantitative description of the numerical solution for three damping conditions by using the BRK5 method is presented in Table 3

\section{Table 2. Simulated results obtained for iterative methods and exact solution with error}

\begin{tabular}{|c|c|c|c|c|c|c|c|}
\hline \multirow{2}{*}{$\begin{array}{c}\text { Time }(\mathrm{t}) \\
(\text { seconds) }\end{array}$} & \multicolumn{2}{|c|}{ Euler } & \multicolumn{2}{|c|}{$R K_{3}$} & \multicolumn{2}{c|}{$B_{5}$} & $\begin{array}{c}\text { Exact } \\
\text { Voltage }(\mathrm{V})\end{array}$ \\
\cline { 2 - 7 } & Voltage (V) & $E_{R}\left(10^{-3}\right)$ & Voltage $(\mathrm{V})$ & $E_{R}\left(10^{-3}\right)$ & Voltage $(\mathrm{V})$ & $E_{R}\left(10^{-3}\right)$ & \\
\hline 0.0 & 0.000000 & 0.000000 & 0.000000 & 0.000000 & 0.000000 & 0.000000 & 0.000000 \\
\hline 0.1 & 0.000000 & 7.550000 & 0.232000 & 5.550000 & 0.448062 & 9.488000 & 0.737550 \\
\hline 0.2 & 0.960000 & 2.195200 & 1.328157 & 3.795000 & 1.665911 & 6.041000 & 2.181952 \\
\hline 0.3 & 2.688000 & 6.488600 & 3.098752 & 5.413400 & 3.470005 & 2.881000 & 4.152886 \\
\hline 0.4 & 4.992000 & 9.169100 & 5.360915 & 2.277600 & 5.688888 & 4.803000 & 6.483691 \\
\hline 0.5 & 7.687680 & 3.723300 & 7.944409 & 8.050400 & 8.167195 & 7.718000 & 9.024913 \\
\hline 0.6 & 10.604544 & 4.204500 & 10.695937 & 0.652000 & 10.768352 & 8.237000 & 11.646589 \\
\hline 0.7 & 13.590528 & 8.875000 & 13.482075 & 7.328000 & 13.376102 & 3.301000 & 14.239404 \\
\hline 0.8 & 16.515133 & 9.770000 & 16.190937 & 3.966000 & 15.895022 & 9.881000 & 16.714903 \\
\hline 0.9 & 19.271197 & 6.292000 & 18.732741 & 2.164000 & 18.250199 & 4.706000 & 19.004905 \\
\hline 1.0 & 21.775442 & 5.153000 & 21.039441 & 0.848000 & 20.386214 & 4.075000 & 21.060289 \\
\hline
\end{tabular}

\section{CONCLUSION}

The transient analysis of the electrical circuit is analyzed using the analytical method, Euler (explicit) method, RK3 methods, and BRK5 method. With the usage of computational software, the process of obtaining results of the transient analysis is done systematically and 
conveniently. From the simulation results, we conclude that numerical solutions are more appropriate in overdamped conditions than in underdamped and critically damped conditions. It has been observed that the BRK5 method is very efficient in solving second-order differential equations. Thus, authors can conclude that by carrying out the transient analysis of a system, we can find out the response of the system by changing the conditions from one steady-state value to another. Observation clearly shows that the under-damped decay is oscillatory and exponential. However, the other two are nonoscillatory exponential decay. The decay in the critically damped case is observed faster than in the over-damped case.

Table 3. Values of three conditions of BRK5 method

\begin{tabular}{|c|l|l|l|}
\cline { 2 - 4 } \multicolumn{1}{c|}{} & \multicolumn{3}{c|}{ Values of BRK5 Method } \\
\hline $\begin{array}{c}\text { Time } \\
(\mathrm{s})\end{array}$ & $\begin{array}{c}\text { Under } \\
\text { damped }\end{array}$ & $\begin{array}{c}\text { Critically } \\
\text { damped }\end{array}$ & $\begin{array}{c}\text { Over } \\
\text { damped }\end{array}$ \\
\hline 0.0 & 0.000000 & 0.000000 & 0.000000 \\
\hline 0.1 & 0.448062 & 0.420556 & 0.372918 \\
\hline 0.2 & 1.665911 & 1.477249 & 1.188828 \\
\hline 0.3 & 3.470005 & 2.925636 & 2.181422 \\
\hline 0.4 & 5.688888 & 4.588992 & 3.226176 \\
\hline 0.5 & 8.167195 & 6.341790 & 4.265703 \\
\hline 0.6 & 10.768352 & 8.096949 & 5.274355 \\
\hline 0.7 & 13.376102 & 9.796018 & 6.241456 \\
\hline 0.8 & 15.892022 & 11.401660 & 7.163347 \\
\hline 0.9 & 18.250199 & 12.891917 & 8.039625 \\
\hline 1.0 & 20.386214 & 14.255861 & 8.871361 \\
\hline
\end{tabular}

\section{ACKNOWLEDGMENT}

Bhogendra Kumar Thakur acknowledges National Youth Council, Sanothimi, Bhaktapur, Nepal for providing financial support as a master thesis grant.

\section{REFERENCES}

Adhikari, B., Basnet, S., Lamichhane, H., \& Khanal, R. (2018). Beta frequency and velocity variation of ions in a magnetized plasma sheath for different obliqueness of the magnetic field. Journal of Institute of Science and Technology, 23(1), 88-92.

Ahamad, N., \& Charan, S. (2019). Study of numerical solution of fourth-order ordinary differential equations (ODEs) by fifth-order Runge-Kutta method. International Journal of Science, Engineering and Technology, 6, 230-237.

Alizadeh, S., Baleanu, D., \& Rezapour, S. (2020). Analyzing transient response of the parallel RCL circuit by using the Caputo-Fabrizio fractional derivative. Advances in Difference Equations, 2020(1), 55. https://doi.org/10.1186/s13662-0202527-0

Balota, A., \& Grebovic, S. (2016). Importance of lightning activity monitoring systems in transient analysis on wind turbine blade. Fourth International Symposium on Environmental Friendly Energies and Applications, 1, 1-6.

Boyce, W. E., \& Di-Prima, R. C. (2012). Elementary differential equations and boundary value problems. New Delhi, India: John Wiley \& Sons, Inc.

Butcher, J.C., \& Goodwin, N. (2008). Numerical methods for ordinary differential equations (Vol. 2). New York, USA: Wiley.

Deshpande, A. S. (2014). Transient analysis of RLC series circuit to step voltage by engineering methods. International Journal of Computational and Applied Mathematics, 9, 63-70.

Elton, M. D. (2017). Analyzation of the resistor-inductorcapacitor circuit. Undergraduate Journal of Mathematical Modeling: One+ Two, 7(2), 1-6.

Falade, K. I., \& Ayodele, V. I. (2019). Numerical solution of currents and voltages flow in electrical circuits (RLC) using the numerical technique. International Journal of Mathematics and Statistics Studies, 7(3), 28-50.

Henry, O., Albert, B., \& Justice, I. (2019). Application of numerical methods in transient analysis. International Journal of Science and Research, 8(5), 2108-2112.

Hossain, M. B., Hossain, M. J., Miah, M. M., \& Alam, M. S. (2017a). A Comparative study on fourth order and Butchers fifth order Runge-Kutta methods with third order initial value problem. Applied and Computational Mathematics, 6(6), 243-253.

Hossain, M. J., Alam, M. S., \& Hossain, M. B. (2017b). A study on numerical solutions of second order initial value problems (IVP) for ordinary differential equations with fourth order and Butchers fifth order Runge-Kutta methods. American Journal of Computational and Applied Mathematics, 7(5), 129137.

Kafle, J., Bagale, L., \& K. C., D. (2020). Numerical solution of parabolic partial differential equation by using finite difference method. Journal of Nepal Physical Society, 6(2), 57-65.

Kafle, J., Thakur, B. K., \& Bhandari, I. B. (2021). Visualization, formulation, and intuitive explanation 
of iterative methods for transient analysis of series RLC circuit. Bibechana, 18 (2), (2021) 9-17.

Kamruzzama, M., \& Nath, M. C. (2018). A Comparative study on numerical solution of initial value problem by using Euler's method, modified Euler's method and Runge-Kutta method. Journal of Computer and Mathematical Sciences, 9(5), 493-500.

Kee, T. A., \& Ranom, R. (2018). Comparison of numerical technique in solving transient analysis of electrical circuits. ARPN Journal of Engineering and Applied Sciences, 13(1), 314-320.

Kendall, A., Weimin, H., \& David, S. (2009). Numerical solution of ordinary differential equations. University of Iowa, Iowa City: A John Wiley \& Sons, Inc.

Lamichhane, H. (2019). Technique for measuring magnitudes and phases of voltage and current in the band-selective parallel LCR circuit. Journal of Institute of Science and Technology, 24(2), 85-90.

Maffezzoni, P., Codecasa, L., \& D’Amore, D. (2007). Time-domain simulation of nonlinear circuits through implicit Runge-Kutta methods. Institute of Electrical and Electronics Engineers Transactions on Circuits and Systems, 54(2), 391-400.
Maria Selvam, A. G., \& Vignesh, D. (2018). Dynamics in a undamped parallel RLC circuit. International Journal of Information and Computing Science, 5(11), 46-49.

Pokhrel, P., Kafle, J., Kattel, P., \& Gaire, H. (2020a). Analysis of blood flow through artery with mild stenosis. Journal of Institute of Science and Technology, 25(2), 33-38.

Pokhrel, P., Lamsal, B., Kafle, J., \& Kattel, P. (2020b). Analysis of displacement of vibrating of mass-spring due to opposition force. Tribhuvan University Journal, 35(1), 21-32.

Santiago, J. (2013). Circuit analysis for dummies. Hoboken, New Jersey, USA: John Wiley \& Sons.

Senthilnatha, C. (2018). Numerical solutions of initial value problems for ordinary differential equations with Euler and higher order of Runge-Kutta methods using Matlab. International Journal of Engineering Science Invention, 7(4), 25-31.

Suhag, A. (2013). Transient analysis of electrical circuits using the Runge-Kutta method and its application. International Journal of Scientific and Research Publications, 3, 486-490. 